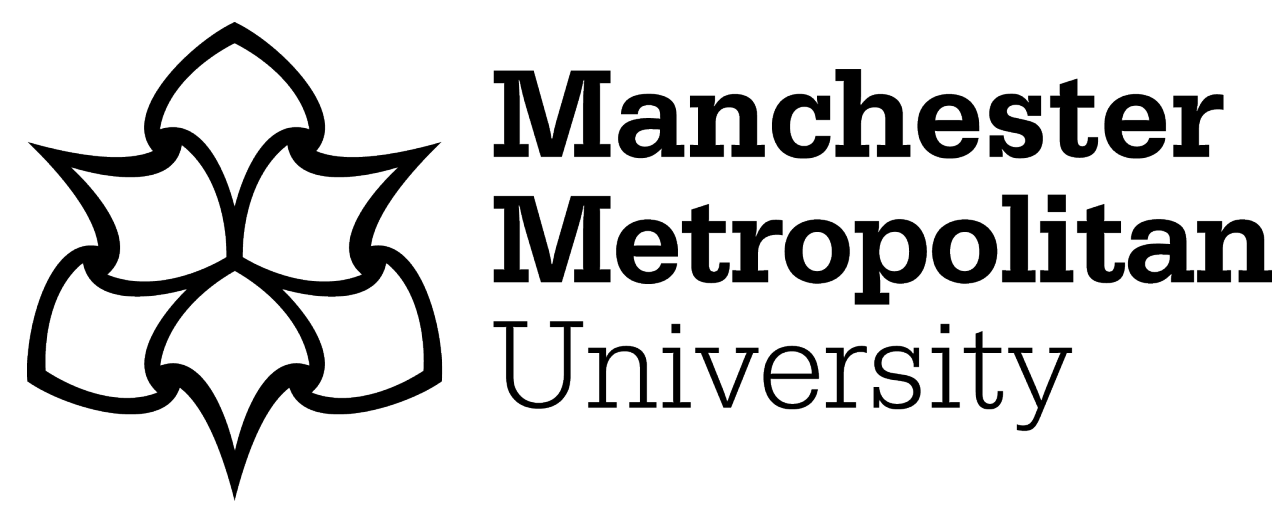

Brindisino, F, Matteuzzi, I, Bury, J, McCreesh, K and Littlewood, C ORCID logoORCID: https://orcid.org/0000-0002-7703-727X (2020) Rotator cuff disorders: A survey of current (2018) Italian physiotherapy practice. Physiotherapy Practice and Research, 41 (1). pp. 11-22. ISSN 2213-0683

Downloaded from: https://e-space.mmu.ac.uk/625658/

Version: Accepted Version

Publisher: IOS Press

DOI: https://doi.org/10.3233/PPR-190141

Please cite the published version 


\section{ROTATOR CUFF DISORDERS: A SURVEY OF CURRENT (2018) ITALIAN PHYSIOTHERAPY PRACTICE}

2

\section{ABSTRACT}

BACKGROUND: Shoulder pain is a common musculoskeletal complaint and disorders of the rotator cuff $(\mathrm{RC})$ are widely regarded as the most common cause. Where clinical care is required, physiotherapists play an integral role. Previous studies have reported physiotherapy practice across other countries as a means of determining current practice and understanding whether practice changes over time in response to emerging research evidence.

AIM: To investigate the practice of Italian physiotherapists, in order to determine current practice for the assessment and management of RC disorders.

METHODS: A cross sectional online survey. A 20-item questionnaire based on one clinical vignette was developed using Survey Monkey Software. Data were analyzed descriptively and difference in proportions between those with a specific education compared to those with no specific education (i.e. "Master's Degree," "1-2 days Training Course" or "Other) were analysed using the chi-squared test.

RESULTS: A total of 805 participants accessed the survey with a total of 436 completed responses (54\%). Fifty-five percent of respondents were male (239/436). Seventy-one percent of respondents (309/436) reported having specific education with regards to $\mathrm{RC}$ disorders. The methods of diagnosing $\mathrm{RC}$ disorders were variable across the respondents as well as the requests for imaging $(184 / 436,42 \%)$, the adoption of manual therapy techniques $(251 / 436,58 \%)$, the duration of treatment (231/436, 53\% visit the patient six times at least) and the administration of physical 
examination test $(175 / 436,40 \%)$. Advice $(279 / 436,64 \%)$ and some form of exercise therapy $(268 / 436,62 \%)$ are the most popular choices of treatment.

DISCUSSION AND CONCLUSION: This current study is the first which described Italian physiotherapy practice for RC disorders. Italian physiotherapy practice is in line with other European countries. Italian physiotherapy practice also aligns with current recommendations with regards to minimal use of imaging and prescription of therapeutic exercise. However, there is heterogeneity across the responses particularly with regards to use of manual therapy, physical examination tests, and duration of treatment.

Furthermore this study is a platform for future research to explore whether Italian physiotherapy practice changes over time.

KEYWORDS: Evidence-Based Practice, Exercise Therapy, Physical Therapy Modalities, Rotator Cuff 


\section{INTRODUCTION}

Shoulder pain is one of the most common musculoskeletal disorders, with up to $26 \%$ of the general population complaining of pain over a one month period in the last year [1]. Rotator cuff (RC) disorders, account for $44 \%$ to $80 \%$ of all shoulder complaints [2], regardless of age and level of activity [3]. Clinically RC disorder can present with pain, weakness and functional difficulties during activities of daily living and sport $[4,5]$. Moreover, for many patients this is not a self-limiting problem, with $50 \%$ of patients reporting ongoing symptoms 12 months after onset [6].

Physiotherapists play an integral role in the management of people with RC disorders and, given the burden of this problem, it is vital that physiotherapists evolve their practice and incorporate research evidence as it emerges. One way of understanding current practice is to undertake a survey. Bury and Littlewood [4] undertook such a survey of UK physiotherapy practice in 2016 as a follow-up to a previous survey [5] to describe practice and understand how practice has evolved over time in line with current recommendations. These surveys reported that practice had evolved between 2011 and 2016 and this evolution was in line with current recommendations $[7,8]$.

The evidence based for the management of $\mathrm{RC}$ disorders is limited but current recommendations include minimal use of imaging, unless red flag pathology (e.g humeral head dislocation or fracture) is expected or the patient does not respond to treatment as expected, and prescripion of progressive therapeutic exercise, although the specifics of this prescription remain less clear. There are clear limitations of commonly used physical examination tests in informing a diagnosis or prognosis $[7,8]$

To our knowledge, no similar survey has been undertaken in relation to Italian physiotherapy practice for RC disorders. Therefore, the aim of this current survey is to 
investigate the practice of Italian physiotherapists for RC disorders, in order to determine current physiotherapy practice and to compare this with practice in other European countries. Furthermore we will analyze differences between respondents classified as having a "specific education" (i.e. physiotherapists that attended specific training courses in the management of RC disorders) and those with "no specific education" when evaluating treatment prescription by respondents in this survey.

\section{METHODS}

\section{Study Design}

The cross-sectional online anonymous survey developed by Bury and Littlewood [4] was adapted, with the permission of the authors, to the Italian language and modified further. Three questions were added to the demographic information, in order to better characterize the personal and educational background of the respondents: age of the respondents, gender and level of qualification.

Moreover, a question to better qualify the respondent's specialization was added: it was "Do you have a specific education in the management of rotator cuff disorders?", to which the participants had four mutually exclusive answer options: "No", "Yes, Master's Degree", "Yes, 1-2-days Training Course", or "Yes, Other".

Furthermore the open question regarding the instructions given to the patient when prescribing exercises, was changed in some of its parts to make it as clear as possible for the respondents. In particular, the item "Frequency" was split into "Daily frequency" and "Weekly frequency", the item "Position" was changed into "Position of exercise execution" and the item "Quality of movement" became "Characteristics of the movement (velocity, fluidity, ...)". 
As per the original survey which focused on RC disorders, a clinical scenario detailing a patient reporting typical signs and symptoms of a $\mathrm{RC}$ disorder (Table 1 , left column) was maintained and translated in Italian (Table 1, right column). This is a recognized way to elicit responses that, as closely as possible, stimulate thought aligned to the decision making process of everyday clinical practice.

\section{TABLE 1 HERE}

This study was approved by the Ethical Committee of the ASL of Lecce (Italy), with protocol number 16 of the 21st February 2018. The full version of the survey is available as Supplementary material.

\section{Sampling and recruitment}

The inclusion criterion was physiotherapists based in Italy. Potential participants were reached through different sources: Facebook, e-mail and Whatsapp, using the researchers' profiles and contacts and an e-mail newsletter promoted by Italian Physiotherapists Association.

In the instructions for filling out the survey there was the specific request that the survey itself was only for physiotherapists. There was also the request to complete the survey only once and we incorporated the function that there could only be one completion per browser or per e-mail address.

Informed consent was implied through completion of the survey.

\section{Sample size}

In this current survey, our approach was to obtain the maximal number of responses in a defined time period. This approach is reflective of other similar surveys $[4,9]$.

\section{Data collection}


Based on previous surveys, a one month was set recognising that most responses to surveys occur within the first one to two weeks [4]. The survey was available via Survey Monkey from the 25th of February 2018 and was closed 2 weeks later, because no further requests to complete the survey were apparent after this time. No reminders for survey completion were sent.

\section{Data analysis}

Data were analyzed using Microsoft Excel. Descriptive statistics are reported. The remaining results were analyzed considering two primary divisions: the first between those having a specific education in RC disorders (SE) and those who had no specific education (NSE), the second comparing (inside the SE group) those specialized through a Master's Degree, those specialized through a 1-2 days Training Course (TC) and those specialized through other means $(\mathrm{O})$. Differences in the proportions of responses between these groups were analyzed using the chi-squared test, completed using "R".

\section{RESULTS}

A total of 805 participants accessed the survey. The respondents who were not physiotherapists based in Italy $(n=11)$ were automatically excluded. Software can not show the response rate of all the questionnaires. For this reason, authors decided to ignore the entire survey questionnaire even if only a single question was unanswered. That is, further 358 were excluded due to incomplete compilation of the survey. The remaining $436(54 \%)$ surveyed were used in the data analysis (Figure 1). 
132 The majority of respondents ( $n=228 / 436 ; 52 \%$;) were under 30 years and are male $133(239 / 436 ; 55 \%)$, received their degree less than ten years previously $(314 / 436 ; 72 \%)$ 134 and were private practitioners (299/436; 69\%).

135 The demographic details of the respondents are presented in table 2 along with 136 educational levels.

\section{TABLE 2 HERE}

Following this descriptive detail, the participants were asked to respond to a series of further practice related questions.

All of the 436 respondents stated that the patient described in table 1 could be treated

142 within physiotherapy.

Would you request any further information or undertake any further clinical tests?

The results of this question are summarized in Figure 2 and Figure 3. Eight percent of respondents (34/436) would not request any further information or undertake any further clinical tests. Thirty-eight percent (167/436) stated that they would request further subjective information and 40\% (175/436) would carry out further physical examination tests. Forty-two percent of respondents (184/436; 33\% SE, 57\% NSE) would request further investigation (e.g. X-ray, ultrasound scan, MRI); of these, a significantly lower proportion belonged to the SE group $(p<0.05)$ and, in particular to Master's degree professionals $(p<0.05)$. Thirty-eight percent $(165 / 436 ; 48 \%$ SE, $22 \%$ NSE) would undertake further rehabilitation classification, e.g. the shoulder symptom 
155

156

157

158

159

160

161

162

163

164

165

166

167

168

169

170

171

172

173

174

175

176

177

modification procedure (SSMP) [10] with a significantly greater prevalence of those with a SE $(p<0.05)$ and particularly those with an Master's degree $(p<0.05)$.

One hundred and ninety-two respondents (44\%) qualified their answers. Regarding subjective information, the most common requests concerned about red flags screening, previous trauma, characterization of pain, associated symptoms, information about the onset, lifestyle, psychosocial screening, and previous treatments and their outcomes.

Further physical examination tests that would be carried out included observation, trigger point palpation, muscle strength tests and specific tests (cuff integrity, impingement). Special orthopaedic tests were mentioned by one-third of respondents (57/192, 30\%), who less frequently belonged to the SE group and to the Master's degree subgroup (22\% Master's degree, 24\% TC, 29\% O).

FIGURES 1 and 2 HERE

Which management strategies would you typically recommend for this patient?

Figure 4 and Figure 5 highlight that treatment for patients with RC disorders was varied among the respondents. Advice and education was most commonly prescribed $(279 / 436 ; 64 \%)$ as well as exercise therapy in all forms. Within the types of exercises, $62 \%(268 / 436)$ would include scapular stabilization exercises, 45\% (197/436) isometric exercises, $41 \%$ (180/436) isotonic exercises and 33\% (143/436) a global kinetic chain approach. A significantly higher proportion of respondents with a NSE ( $p=0.04)$ would include isotonic exercises compared to those with SE, but inside the SE group this choice is particularly common among the Master's degree professionals $(63 \% p=$ $0.0004)$ 
Another popular treatment option was mobilization (251/436, 58\%; 52\% SE; 67\% NSE) with less of those respondents in the SE group choosing this option $(p=0.003)$. Massage (including deep friction massage/soft-tissue release) would be utilised by $41 \%(179 / 436)$ of respondents. Only $6 \%(26 / 436)$ of all physiotherapists would suggest referral for further investigation.

FIGURES 4 and 5 HERE

\section{When prescribing exercises, what instructions do you generally give to the} patient?

Less than $40 \%(174 / 436)$ responded to this open-ended, non-mandatory question. In this case a qualitative analysis of the answers was undertaken. In relation to pain, the majority of respondents would expect it to be present while exercising. Exercising in the pain-free range was expressed by $41 \%$ of the respondents (179/436), of which a higher proportion belonged to the NSE group. Moreover, among the SE group components, exercising in the pain-free range was less supported by Master's degree physiotherapists (19\%).

Regarding load, most respondents $(105 / 350,30 \%)$ suggested gradual progression when loading and adjusting it with respect to the patient's abilities $(76 / 350,22 \%)$ and under the guidance of acceptable levels of pain (62/350, $18 \%)$.

In relation to repetitions, most respondents would indicate up to 10 times $(143 / 366$, $39 \%)$ and/or up to three sets $(89 / 366,24 \%)$ and often to be guided by fatigue $(65 / 366$, $18 \%)$. Less frequently recommended were up to 15 repetitions $(56 / 366,15 \%)$, and guided by pain $(24 / 366,7 \%)$. 
In terms of frequency, the most common response was two times per day $(123 / 358$, $34 \%)$, followed by once $(87 / 358,24 \%)$ and three times per day $(68 / 358,19 \%)$.

The majority of respondents suggested exercising every day (158/346, 46\%). There was no overall difference between SE and NSE groups,

In terms of position of exercise execution, the majority of respondents preferred exercises in standing (130/334, 39\%). Some chose a comfortable position in order to control compensation $(41 / 334,12 \%)$ or making it functional to the provocative task $(39 / 334,12 \%)$ or even changing position following a gravity progression $(21 / 334,6 \%)$. The functional approach was supported mostly by the members of the SE group and in particular by the Master's degree professionals (23/84, 27\%).

In relation to the characteristics of movement a slow (187/321, 58\%), fluid (102/321, $32 \%)$ and controlled $(87 / 321,27 \%)$ movement was preferred in most cases. Slowness and movement control were more frequently mentioned by the NSE group, while the SE group and especially those with a Master's degree, emphasised fluidity and preferred exercises at variable speed.

Concerning the onset of fatigue, most respondents consider it to be necessary to progression $(53 / 260,20 \%)$ or at least normal when performing the last repetitions $(27 / 260,10 \%)$. On the contrary, the need to reduce repetitions or propose rest when fatigue appears $(101 / 260,39 \%)$ was less frequently expressed.

In relation to progression of exercises, the majority of respondents stated that they would progress as pain allows $(74 / 232,32 \%)$ or as fatigue allows $(41 / 232,18 \%)$ and by increasing the load $(72 / 232,31 \%)$.

\section{What advice would you typically offer this patient?}


Italian physiotherapists would choose to offer a wide variety of advice about different topics: advice about a home exercise program (382/436, 88\%) was the most popular choice followed by the use of written advice about self-management (157/436, 36\%) and counseling about relative rest and movement (163/436, 37\%).

\section{After the initial assessment, how would you typically deliver this treatment?}

The results of this question are summarized in Table 3. The majority of the respondents stated a preference for a combination of face-to-face appointments and selfmanagement at home (350/436, 80\%; $86 \%$ SE; $72 \%$ NSE) with this choice significantly more prevalent in NSE group members $(p=0.005)$. A lower percentage of total respondents chose only individual face-to-face appointments (146/436, 36\%; $27 \%$ SE; $44 \%$ NSE), with this choice significantly more prevalent in SE group members ( $p=$ 0.0002). SE group members were more likely to choose "Home Exercise Programme" $(p=0.01)$ and "Written advice on Self Management" $(p=0.02)$ as advice for this kind of patient, than those with NSE. (Figure 6).

\section{FIGURE 6 HERE}

\section{How many times and how long would you typically expect to see this patient?}

The results of these questions are summarized in Table 3. The majority of respondents would see this patient 5-6 times $(119 / 436,27 \%)$ and over a six week period of time with no statistically significant difference between groups $(p=0.08)$. A three month treatment program was indicated only by $19 \%$ of all respondents (84/436); of which a greater percentage were SE professionists $(p=0.001)$ and predominantly members of the Master's degree subgroups (37/107, 35\% Master's degree; $p=0.02)$. 
Would you expect this patient to recover with the prescribed physiotherapy?

252

The most common opinion on this question was that the patient would recover with three months of physiotherapy $(332 / 436,76 \%)$, while a smaller amount of respondents suggested six months $(87 / 436,20 \%)$.

\section{What would be your main treatment goals for this patient?}

This was an open-ended question and a qualitative analysis of the answers was undertaken. Eighty-two percent (357/436) of the respondents reported at least one treatment goal. The most recurrent themes were pain reduction, patient education and increase in the pain-free range of motion.

\section{Would you consider referring this patient for a surgical opinion?}

The vast majority of respondents stated that they would not consider a surgical opinion (271/436, 62\%). Among the SE subgroups the Master's degree professionals were significantly more likely to not refer the patient $(83 / 107,78 \%$ Master's degree; $p=$ 0.0008) compared to the other SE physiotherapists.

Referral was considered because of failure of conservative treatment $(102 / 163,63 \%)$, or for severe functional impairment $(23 / 163,14 \%)$. 


\section{Do you think that research would benefit your practice with regard to rotator cuff} disorders?

The vast majority of respondents considered that further research would benefit their practice $(395 / 436,91 \%)$. In this case a qualitative analysis of the answers was undertaken: one hundred and fifty five respondents suggested areas for further research such as ideal exercise parameters, prognostic factors and the role of fascial dysfunctions in the onset and maintenance of RC disorders.

\section{DISCUSSION}

This study provides new information regarding Italian physiotherapists' clinical practice in relation to disorders of the $\mathrm{RC}$ and represents a starting point to understand how Italian physiotherapy practice might change over time.

This survey reports that Italian physiotherapy practice aligns with current recommendations with regards to minimal use of imaging, and prescription of advice and therapeutic exercise that are the most popular choices of treatment.

Exercise is currently recommended as the mainstay of physiotherapy practice for the management of RC disorders [8]. The findings of this survey reflect current recommendations [8-12]. However, there is heterogeneity with regards to other factors including use of physical examination tests for diagnosing RC disorders and use of manual therapy in management.

There are many differences between physiotherapists with SE and NSE, and some of these are significant. Physiotherapists with SE responded more in line with current recommendations, than those with NSE, indicating that further specialist education provides a beneficial effect in terms of the implementation of evidence based practice. 
This differential response is similar to other European surveys of current physiotherapy practice [9].

In relation to clinical assessment and treatment, the results of the present study elicit several observations. In the clinical assessment $40 \%$ of respondents stated that they would have carried out further physical examination tests. Although comments included screening of the cervical/thoracic spine, observation and palpation, one-third of respondents, mainly those with NSE, expressly mentioned performing specific orthopaedic tests. These findings are in keeping with the UK survey [4], but in contrast with current evidence that indicates the poor validity and reliability of these tests $[11,12]$.

Furthermore, $42 \%$ of the respondents would request further investigation (X-ray, MRI, ultrasound scan) and a significantly lower proportion of these have a specific education (33\%) and followed a Master's degree (8\%). The utility of diagnostic imaging in patients with atraumatic shoulder pain is challenged by current evidence due to the presence of abnormal morphology in asymptomatic individuals $[13,14,15]$. These findings, similar to the results found in the UK by Littlewood et al. [5] more than in 2016 [4], suggest mainly that professionals who did not have a Master's degree are more likely to rely on imaging to make a diagnosis.

Thirty-eight percent of physiotherapists in the current study would use a rehabilitation classification, for example the SSMP, in their clinical assessment, particularly those with a SE and mainly Master's degree ones (respectively $48 \%$ and $73 \%$ ). This might reflect the clear limitations of many current approaches to the assessment of atraumatic shoulders, however the validity and reliability of these classification systems requires further investigation, which is currently conflicting [15]. 
Concerning treatment, Italian physiotherapists choose a wide selection of interventions with advice, education and some form of exercise the most common. These findings are in line with those of Bury and Littlewood [4] and current evidence, with studies identifying exercise therapy as a promising treatment approach for RC disorders [7,11]. The variability in exercise prescription parameters reported in this survey reflects current uncertainty about the optimal approach [16]. For example, $40 \%$ would instruct pain-free exercise, but the majority of respondents would expect some level of pain, mainly among physiotherapists with a SE and particularly with a Master's degree. This is in line with Bury and Littlewood study [4] and showed that physiotherapists in these two surveys are more likely to prescribe exercises into pain. Current evidence also supports painful exercise in musculoskeletal disorders in the short-term [17], although further research is needed to investigate how it applies specifically to RC disorders. Regarding the type of exercise, scapular exercises were most common, although isotonic, isometric and global kinetic chain exercises were also popular, reflecting the same research uncertainty mentioned above [18].

Italian physiotherapists would also include manual therapy techniques in their rehabilitation program, which is not currently supported by strong evidence in the long term $[19,20]$, and was less frequently used as a modality by comparison in the UK survey [4]. One possible explanation for this, is that hands-on techniques still represent a core element of musculoskeletal physiotherapy practice appreciated by patients and widely taught in educational program and clinical professional development training in Italy [21].

With respect to advice, Italian physiotherapists would offer this on a wide variety of topics, among which "home exercise program" was the main one. Moreover, the most popular choice of treatment delivery was a combination of supervised treatment and a 
home exercise program. These two findings reflect research evidence that supervised and self-managed exercise do not differ $[22,23]$. Group exercise was mentioned by a very small number of participants, interesting given the emerging evidence for the effectiveness of physiotherapy-led group exercise in various musculoskeletal conditions, including shoulder pain $[24,25]$.

Concerning the treatment period, the majority of Italian physiotherapists would treat the patient up to a six-week period, while only around $20 \%$ for a three-month period. There is no unanimity in literature on this topic, though it appears that three months could be optimal for conservative treatment to reveal its efficacy [16].

\section{Strengths and limitations of this study}

A strength of this paper is the large number of respondents and the vignette-based methodologies that are used to examine decision making processes and clinical judgments made by health professionals. Vignette studies have been recognized as a "hybrid" methodology that inherits the external validity strengths of survey research and the internal validity strengths of experimental methods, highly generalizable to real world behavior among clinicians [26]. Another original strength of this study is that the respondents were divided into those with SE, and with NSE, in order to understand if having a SE can lead to practice which more closely aligns to current recommendations. Furthermore in the context of other studies, the current survey is one of the largest that has been conducted worldwide in this clinical area with a wide variety of respondents, but, despite this, there are some limitations. The number of participants who failed to complete the survey was quite large (369/805; 46\%). The reasons for non-completion are unclear but the large number of participants who 
completed and their varied backgrounds offers some reassurance with regard to the validity of these findings.

\section{Future research}

The survey findings support the need for more high-quality studies to help establish a reliable method of assessment, define the parameters of exercise therapy and clarify the actual benefit of including therapies other than exercise in the rehabilitation protocol, which remains open to question by the current evidence base for RC disorders.

\section{CONCLUSION}

This survey is the first to describe Italian physiotherapy practice for RC disorders.

The present study found that Italian physiotherapists are in line with current evidence in using mainly education, advice and exercise therapy, though without a consensus on the parameters of exercise prescription. It also found that physiotherapists with a specific education, and particularly those with a Master's degree, seem to be better aligned with current evidence for what concerns the assessment of these patients and less reliance on imaging or orthopedic tests.

\section{ETHICS APPROVAL AND CONSENT TO PARTICIPATE}

This study was approved by the Ethical Committee of the ASL of Lecce (Italy), with protocol number 16 of the 21st February 2018.

Informed consent of participant to the survey was implied through voluntary submission of the same survey, without the need of a written consent form 
CONSENT FOR PUBLICATION

393 Not applicable

394

395

CONFLICT OF INTEREST and SOURCE OF FUNDING

396

Authors decleares no competing interest, no conflict of interest or source of funding

397

398

MANUSCRIPT CATEGORY

399 This paper is a Survey (Original research) and it is NOT based on a previous

400 communication to a society or meeting

401

402

\section{AVAILABILITY OF DATA AND MATERIAL}

403

The full version of the survey is available as Supplementary material (See Appendix).

404

405

\section{ACKNOWLEDGEMENTS}

406

Heartfelt thanks are owed to Lorenza Maistrello, who was fundamental to perform the

407 statistical analysis, to Marco Segat and Mattia Salomon who significantly contributed 408 in sharing the survey and of course to all of the Italian physiotherapists who 409 participated, making it all possible. 
$412 \quad A D L=$ Activities of daily living

413 AIFI = Associazione Italiana Fisioterapisti (Italian Physiotherapists Association)

$414 \quad \mathrm{RC}=$ Rotator cuff

415 SE $=$ Specific education

$416 \quad$ NSE $=$ No specific education

$417 \quad$ TC $=$ Training Course

$418 \quad \mathrm{O}=$ Other

419 SSMP = Shoulder Symptoms Modification Procedures

420 SAT $=$ Scapular Assistance Test 


\section{REFERENCES}

422

423

1- Luime JJ, Koes BW, Hendriksen IJ, et al. Prevalence and incidence of shoulder pain in the general population; a systematic review. Scandinavian Journal of Rheumatology. 2004; 33(2):73-81.

2- Kooijman M, Swinkels I, van Dijk C, Patients with shoulder syndromes in general and physiotherapy practice: an observational study. BMC Musculoskeletal Disorders. 2013; 8; 14:128. doi: 10.1186/1471-2474-14-128

3- Grant HJ, Arthur A, Pichora DR. Evaluation of Interventions for Rotator Cuff Pathology: a systematic review. Journal of Hand Therapy. 2004; 17:274-299. doi: 10.1197/j.jht.2004.02.013

4- Bury J, Littlewood C. Rotator cuff disorders: a survey of current (2016) UK physiotherapy practice. Shoulder and Elbow. 2018; 10, 52-61 doi: $10.1177 / 1758573217717103$

5- Littlewood C, Lowe A, Moore J. Rotator cuff disorders: a survey of current UK physiotherapy practice. Shoulder \& Elbow. 2012; 4;64-71 https://doi.org/10.1111/j.1758-5740.2011.00164.x

6- Winters J, Sobel J, Groenier K, et al. The long-term course of shoulder complaints: a prospective study in general practice. Rheumatology.1999; 38:160-3.

7- Abdulla SY, Southerst D, Côté $P$, et al. Is exercise effective for the management of subacromial impingement syndrome and other soft tissue injuries of the shoulder? A systematic review by the Ontario Protocol for Traffic Injury Management (OPTIMa) Collaboration. Manual Therapy. 2015; 20(5), 646-56. doi: 10.1016/j.math.2015.03.013. 
8- Blume C, Wang-Price S, Trudelle-Jackson E, et al. Comparison of eccentric and concentric exercise interventions in adults with subacromial impingement syndrome. International Journal Sports Physical Therapy. 2015; 10: 441-455.

9- Pieters L, Voogt L, Bury J, et al. Rotator CUFF disorders: A survey of current physiotherapy practice in Belgium and the Netherlands. Musculoskelet Sci Pract. 2019; 17; 43:45-51.

10- Lewis, JS. Rotator cuff tendinopathy/subacromial impingement syndrome: is it time for a new method of assessment? British Journal of Sports Medicine. 2009; 43: 259-264 doi: 10.1136/bjsm.2008.052183

11-Diercks R, Bron C, Dorrestijn O, et al. Guideline for diagnosis and treatment of subacromial pain syndrome. Acta Orthopaedica. 2014; 85: 314-322. doi: 10.3109/17453674.2014.920991.

12- Hegedus EJ, Goode AP, Cook CE, et al. Which physical examination tests provide clinicians with the most value when examining the shoulder? Update of a systematic review with meta-analysis of individual tests. British Journal Sports Medicine. 2012; 46: 964-978. doi: 10.1136/bjsports-2012-091066

13- Braman JP, Zhao KD, Lawrence RL, et al. Shoulder impingement revisited: evolution of diagnostic understanding in orthopedic surgery and physical therapy. Medical \& Biological Engeneering \& Computing. 2012; 52(3):211-9. doi: $10.1007 / s 11517-013-1074-1$

14- Yamamoto A, Takagishi K, Kobayashi T, et al. Factors involved in the presence of symptoms associated with rotator cuff tears: a comparison of asymptomatic and symptomatic rotator cuff tears in the general population. Journal Shoulder Elbow Surgeon. 2012; 20: 1133-1137 doi: 10.1016/j.jse.2011.01.011 
15- Girish G, Lobo LG, Jacobson JA, et al. Ultrasound of the shoulder: asymptomatic findings in men. American Journal of Roentgenology. 2011; 197: 713-719. doi: 10.2214/AJR.11.6971

16- Meakins A, May S, Littlewood C. Reliability of the Shoulder Symptom Modification Procedure and association of within-session and between-session changes with functional outcomes. BMJ Open Sport Excercise Medicine. 2018; 10;4(1) doi: 10.1136/bmjsem-2018-000342.

17- Littlewood C, Malliaras P, Chance-Larsen K. Therapeutic exercise for rotator cuff tendinopathy: a systematic review of contextual factors and prescription parameters. International Journal of Rehabilitation Research. 2015; 38(2):95106. doi: $10.1097 / M R R .0000000000000113$

18- Smith BE, Hendrick P, Smith TO, ety al. Should exercises be painful in the management of chronic musculoskeletal pain? A systematic review and metaanalysis. British Journal Sports Medicine. 2017; 51(23):1679-1687. doi: 10.1136/bjsports-2016-097383

19- Turgut E, Duzqun I, Baltaci G. Effects of Scapular Stabilization Exercise Training on Scapular Kinematics, Disability, and Pain in Subacromial Impingement: A Randomized Controlled Trial. Archives of Physical Medicine Rehabilitation. 2017;98(10):1915-1923.e3. doi: 10.1016/j.apmr.2017.05.023

20- Hawk C, Minkalis AL, Khorsan R, et al. Systematic Review of Nondrug, Nonsurgical Treatment of Shoulder Conditions. Journal of Manipulative and Physiological Therapeutics. 2017; 40(5):293-319. doi: 10.1016/j.jmpt.2017.04.001 
21- Geri T, Viceconti A, Minacci M, et al. Manual therapy: Exploiting the role of human touch. Musculoskeletal Science and Practice. 2019; 25: 102044. doi: 10.1016/j.msksp.2019.07.008

22- Steuri R, Sattelmayer M, Elsig S, et al. Effectiveness of conservative interventions including exercise, manual therapy and medical management in adults with shoulder impingement: a systematic review and meta-analysis of RCTs. British Journal Sports Medicine. 2017; 51(18):1340-1347. doi: 10.1136/bjsports-2016-096515

23- Granviken F, Vasseljen O. Home exercises and supervised exercises are similarly effective for people with subacromial impingement: a randomised trial. Journal of Physiotherapy. 2015;61(3):135-41. doi: 10.1016/j.jphys.2015.05.014.

24- Littlewood C, Bateman M, Brown K, et al. A self-managed single exercise programme versus usual physiotherapy treatment for rotator cuff tendinopathy: a randomised controlled trial (the SELF study). Clinical Rehabilitation. 2016; 30: 686-696. doi: 10.1177/0269215515593784

25-Barrett E, Conroy C, Corcoran M, et al. An evaluation of two types of exercise classes, containing shoulder exercises or a combination of shoulder and thoracic exercises, for the treatment of nonspecific shoulder pain: A case series. Journal Hand Therapy. 2017; 31(3):301-307 doi: 10.1016/j.jht.2017.10.011

26-Evans SC, Roberts MC, Keeley JV, et al. Vignette methodologies for studying clinicians'decision-making: Validity, utility, and application in ICD-11 field studies. International Journal of Clinical and Health Psychology. 2015; 15, 160 170 doi: http://dx.doi.org/10.1016/j.jjchp.2014.12.001 
TABLE 1: The clinical scenario about a patient reporting typical signs and symptoms of an Rotator Cuff disorders

\section{Clinical scenario of a typical patient with a RC disorder (original)}

A 54-year-old man presents to you with a 9month history of right shoulder pain of gradual, insidious onset. The pain is located over the anterolateral aspect of his shoulder, with no radiation of symptoms. He describes the pain as intermittent, made worse by reaching up, lifting, reaching behind his back and lying on this side. Symptoms ease with rest. He has had no previous treatment or investigations for this problem so far and is otherwise in good general health. His occupation as a warehouse operative involves some heavy lifting onto shelves, which he is continuing to do. On examination, observation is unremarkable. Cervical spine range of movement is full and pain-free. Active shoulder movements are full, but with a painful arc on active abduction between 60" and 120". Passive shoulder movements are largely maintained. Isometric muscle testing produced pain on abduction and lateral rotation, with a power of $4 / 5$ noted for both.
Clinical scenario of a typical patient with a RC disorder (Italian translation)

Un uomo di 54 anni si presenta alla sua attenzione per un dolore alla spalla destra che persiste da 9 mesi ed ha avuto un esordio insidioso e graduale. II dolore è localizzato sull'aspetto anterolaterale della spalla, senza sintomi irradiati. Il paziente riferisce che i sintomi sono intermittenti ed aumentano con l'elevazione del braccio, il sollevamento di pesi, portando la mano dietro la schiena ed in posizione distesa sul fianco destro, mentre si attenuano con il riposo. Il paziente non ha effettuato altre indagini o altri trattamenti per questo problema prima d'ora e riferisce di essere in un buono stato di salute generale. Lavora come magazziniere, il che prevede il sollevamento di carichi pesanti su degli scaffali e non ha interrotto l'attività lavorativa. All'osservazione non emergono dati rilevanti. I movimenti cervicali attivi e passivi risultano completi e non evocano nessun sintomo. Anche il ROM attivo della spalla destra appare completo, ma presenta un arco doloroso fra i $60^{\circ}$ e i $120^{\circ}$ di abduzione. II ROM passivo è complessivamente mantenuto. Si evoca dolore alla contrazione isometrica in abduzione e rotazione esterna e risultano entrambe deficitarie per quanto riguarda la forza, con un grading di 4/5 per entrambe. 
529 TABLE 2: Respondents demographics

530

\begin{tabular}{|lcc|}
\hline Age & Frequency & $\%$ \\
\hline $20-25$ & 85 & $19.5 \%$ \\
$26-30$ & 143 & $32.8 \%$ \\
$31-35$ & 82 & $18.8 \%$ \\
$36-40$ & 55 & $12.6 \%$ \\
\hline 41 & 71 & $16.3 \%$ \\
\hline Gender & 239 & $54.8 \%$ \\
\hline Male & 197 & $45.2 \%$ \\
\hline Female & & \\
\hline Level of education & 248 & $54.8 \%$ \\
\hline Bachelor's Degree & 32 & $6.2 \%$ \\
Master of Science Degree & 2 & $0.4 \%$ \\
PhD in Physiotherapy & 139 & $30.9 \%$ \\
Master's Degree & 39 & $7.7 \%$ \\
\hline Other & & \\
\hline Years from graduation & 177 & $40.6 \%$ \\
\hline$<5$ & 137 & $31.4 \%$ \\
6 6-10 & 55 & $12.7 \%$ \\
$11-15$ & 26 & $5.9 \%$ \\
$16-20$ & 41 & $9.4 \%$ \\
\hline$>20$ & & \\
\hline Role/practice setting & 59 & $8.5 \%$ \\
\hline Hospital & 143 & $21.7 \%$ \\
Private practice & 299 & $56.6 \%$ \\
Freelance & 56 & $8.8 \%$ \\
Sports team & 18 & $2.1 \%$ \\
\hline Teacher/researcher & 32 & $3.3 \%$ \\
\hline Other & 171 & $29.2 \%$ \\
\hline Specific education & 167 & $24.5 \%$ \\
\hline No & 42 & $36.7 \%$ \\
\hline Master's Degree & $9.6 \%$ \\
\hline $1-2$ days Training Course & & \\
Other & & \\
\hline
\end{tabular}


535 TABLE 3: Treatment parameters

\begin{tabular}{|c|c|c|c|c|c|c|}
\hline & \multicolumn{2}{|c|}{ SE (n=267) } & \multicolumn{2}{|c|}{ NSE $(n=171)$} & \multicolumn{2}{|r|}{ Total } \\
\hline Treatment setting $(n=436)$ & $\mathrm{n}$ & $\%$ & $\mathrm{n}$ & $\%$ & $\mathrm{n}$ & $\%$ \\
\hline Face-to-face appointments & 72 & $27.0 \%$ & 76 & $44.4 \%$ & 146 & $33.5 \%$ \\
\hline Home-based program & 2 & $0.8 \%$ & 4 & $2.3 \%$ & 6 & $1.4 \%$ \\
\hline $\begin{array}{l}\text { Face-to-face appointments and home-based } \\
\text { program }\end{array}$ & 229 & $85.8 \%$ & 123 & $71.9 \%$ & 350 & $80.3 \%$ \\
\hline Group class(es) & 8 & $3.0 \%$ & 3 & $1.8 \%$ & 11 & $2.5 \%$ \\
\hline Other & 3 & $1.1 \%$ & 0 & $0.0 \%$ & 3 & $0.7 \%$ \\
\hline Number of times typically seen $(n=436)$ & $\mathrm{n}$ & $\%$ & $n$ & $\%$ & $n$ & $\%$ \\
\hline Once & 1 & $0.4 \%$ & 1 & $0.6 \%$ & 2 & $0.5 \%$ \\
\hline Twice & 25 & $9.4 \%$ & 13 & $7.6 \%$ & 37 & $8.5 \%$ \\
\hline 3 or 4 times & 36 & $13.5 \%$ & 39 & $22.8 \%$ & 75 & $17.2 \%$ \\
\hline 5 or 6 times & 78 & $29.2 \%$ & 42 & $24.6 \%$ & 119 & $27.3 \%$ \\
\hline 7 or 8 times & 41 & $15.4 \%$ & 23 & $13.5 \%$ & 64 & $14.7 \%$ \\
\hline 9 or 10 times & 46 & $17.2 \%$ & 28 & $16.4 \%$ & 74 & $16.8 \%$ \\
\hline More than 10 times & 40 & $15.0 \%$ & 25 & $14.6 \%$ & 64 & $14.9 \%$ \\
\hline Typical duration of treatment & $\mathrm{n}$ & $\%$ & $\mathrm{n}$ & $\%$ & $\mathrm{n}$ & $\%$ \\
\hline Up to 3 weeks & 35 & $13.0 \%$ & 24 & $14.0 \%$ & 59 & $13.5 \%$ \\
\hline Up to 6 weeks & 76 & $28.5 \%$ & 63 & $36.8 \%$ & 139 & $31.9 \%$ \\
\hline Up to 8 weeks & 64 & $24.0 \%$ & 43 & $25.2 \%$ & 106 & $24.3 \%$ \\
\hline Up to 3 months & 65 & $24.3 \%$ & 20 & $11.7 \%$ & 84 & $19.3 \%$ \\
\hline Up to 6 months & 5 & $1.9 \%$ & 8 & $4.7 \%$ & 13 & $3.0 \%$ \\
\hline Up to 12 months & 0 & $0.0 \%$ & 2 & $1.2 \%$ & 2 & $0.5 \%$ \\
\hline Other & 22 & $8.2 \%$ & 11 & $6.4 \%$ & 33 & $7.6 \%$ \\
\hline
\end{tabular}


548

549 FIGURE 1: FLOW CHART: partecipants inclusion criteria

550

$$
\mathrm{n}=11
$$

Excluded because not physiotherapists based in Italy

$N=436$

Respondents included in data analysis

551

$$
\mathrm{n}=358
$$

Excluded because did not complete the survey

552

553

NOTE: Identification of respondents included

554

555

556

557

558

559

560

561 
FIGURE 2: Q.9: Would you request any further information or undertake any

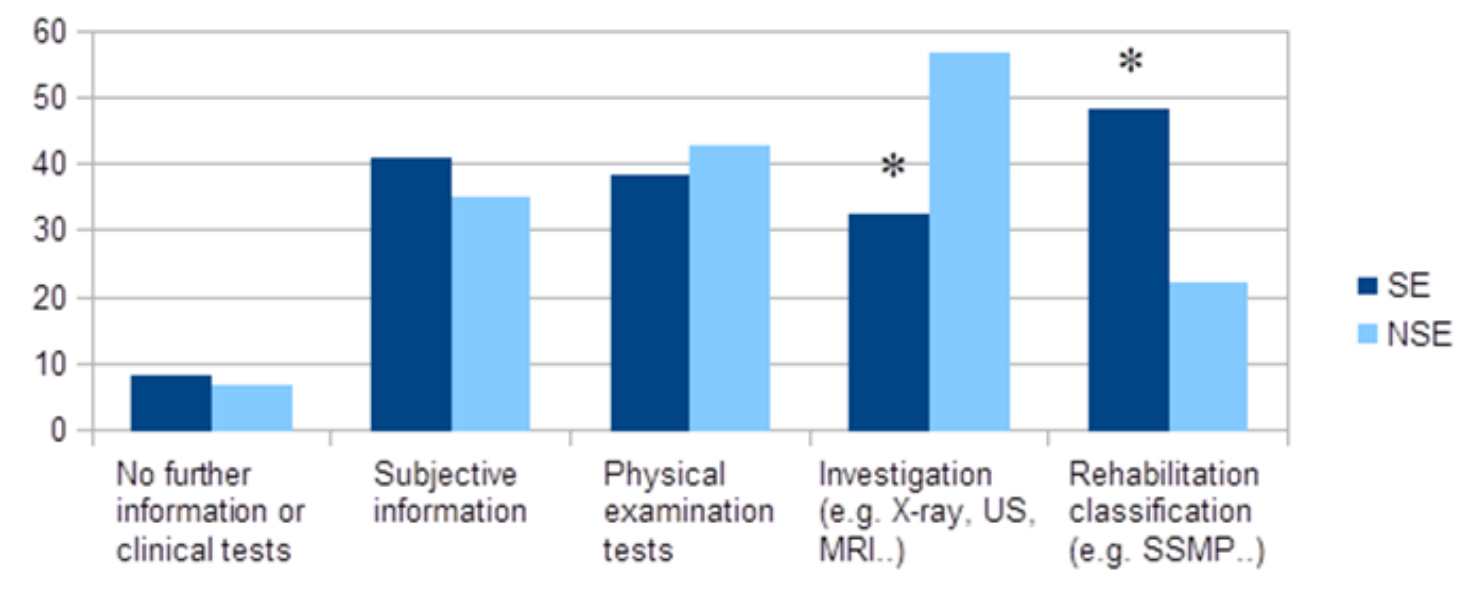

NOTE: Q, Question number; SE, respondents who stated a specific education in rotator cuff disorders; NSE, respondents who stated no specific education in rotator cuff disorders; SSMP, Shoulder Symptom Modification Procedure; US, Ultrasound 
FIGURE 3: Q.10, SE subgroup: Would you request any further information or 587 undertake any further clinical tests?

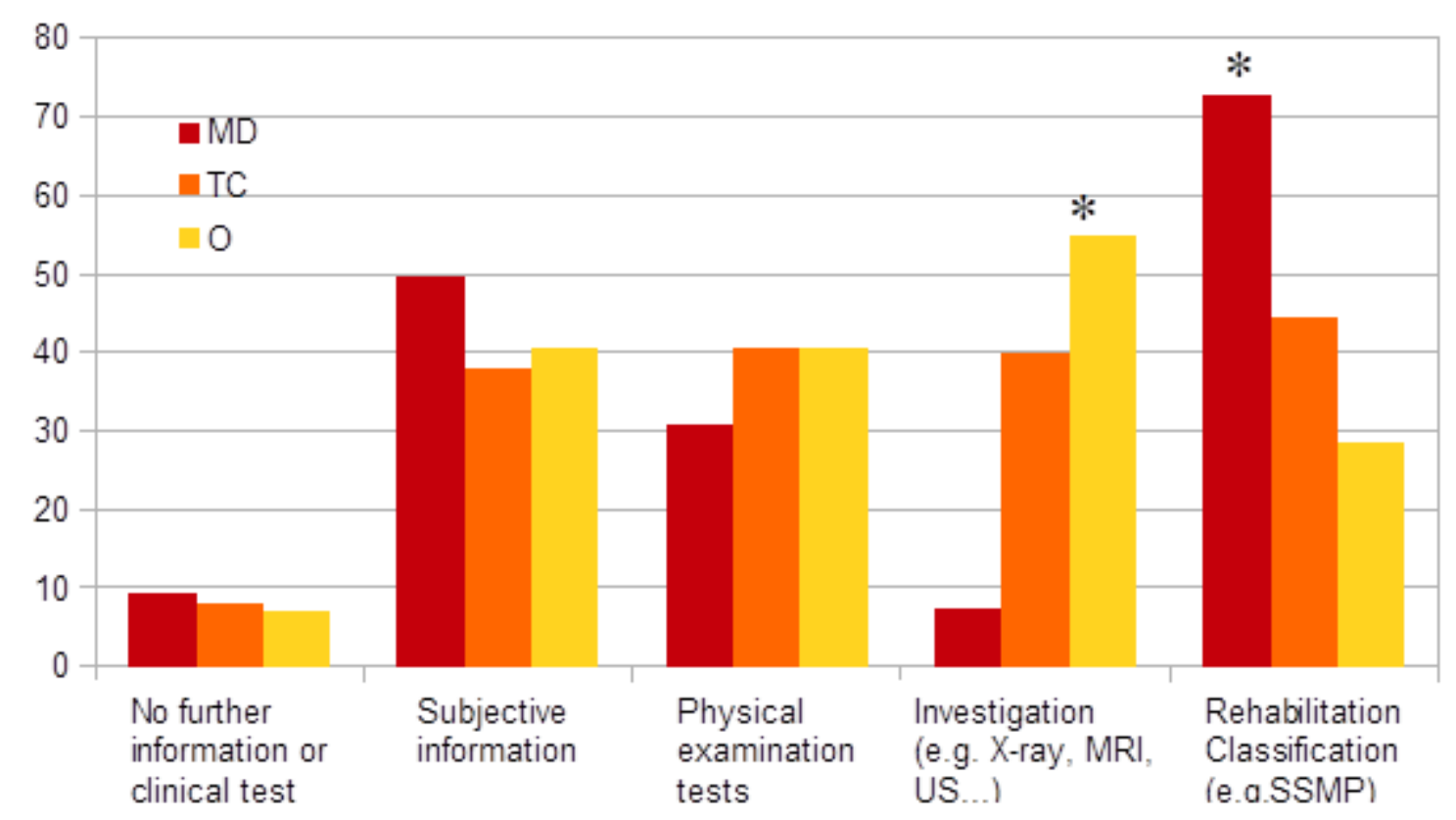

NOTE: Q, Question number; MD, Master's Degree; TC, 1-2 days Training Course; O, 

for this patient?

Sc apular

Mobilization

Isometric ex.

Isotonic ex.

Massage

Cervic al/thorac ic

Kinetic Chain

Taping

Manipulation

Stretching

Cold Therapy

Other Exerc ise

Heat Therapy

Elec trotherapy

Isokinetic ex.

Other

Investigation/option

No treatment
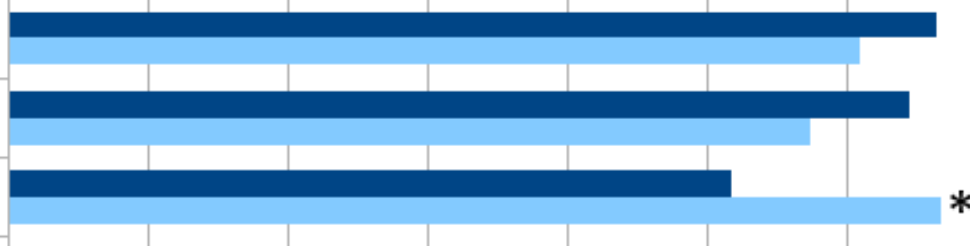

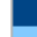

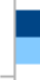
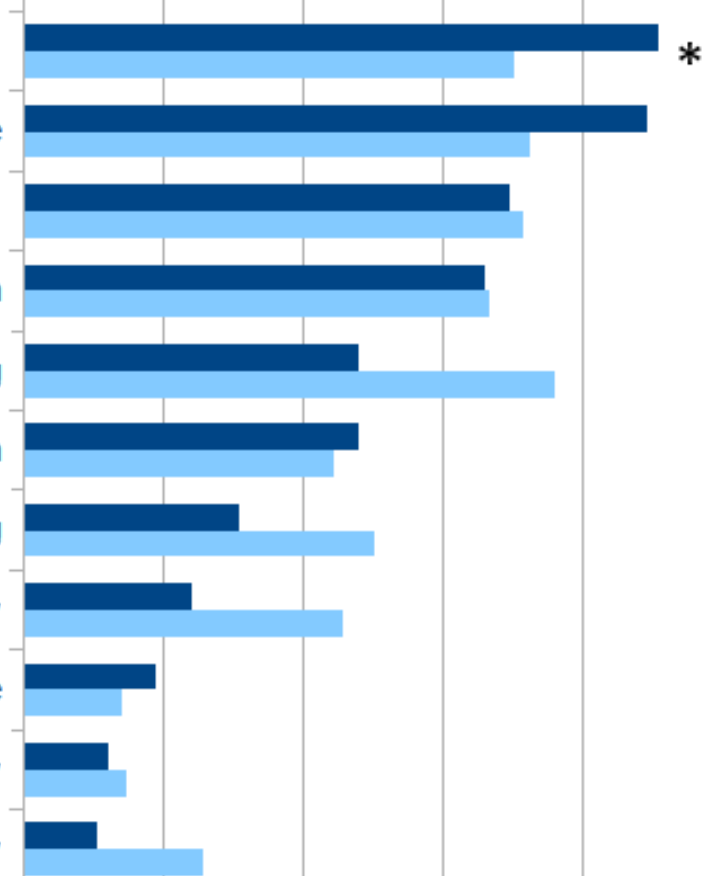

604

NOTE: Q, Question number; SE, respondents who stated a specific education in rotator cuff disorders; NSE, respondents who stated no specific education in rotator cuff disorders; Ex, Exercises; * , statistically significant difference 


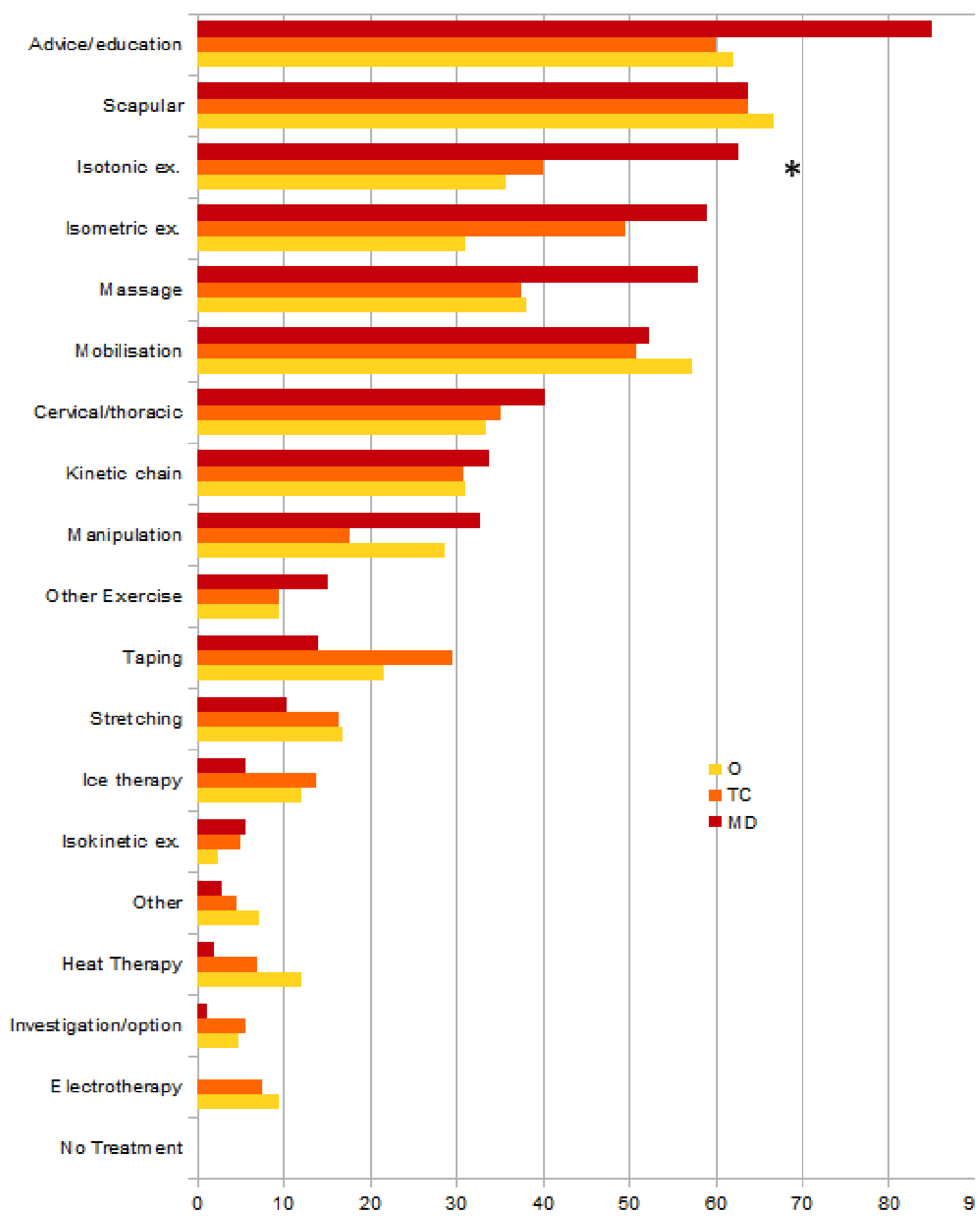

617 NOTE: Q, Question number; MD, Master's Degree; TC, 1-2 days Training Course; O, 618 Other; Ex, exercises; * , statistically significant difference. 


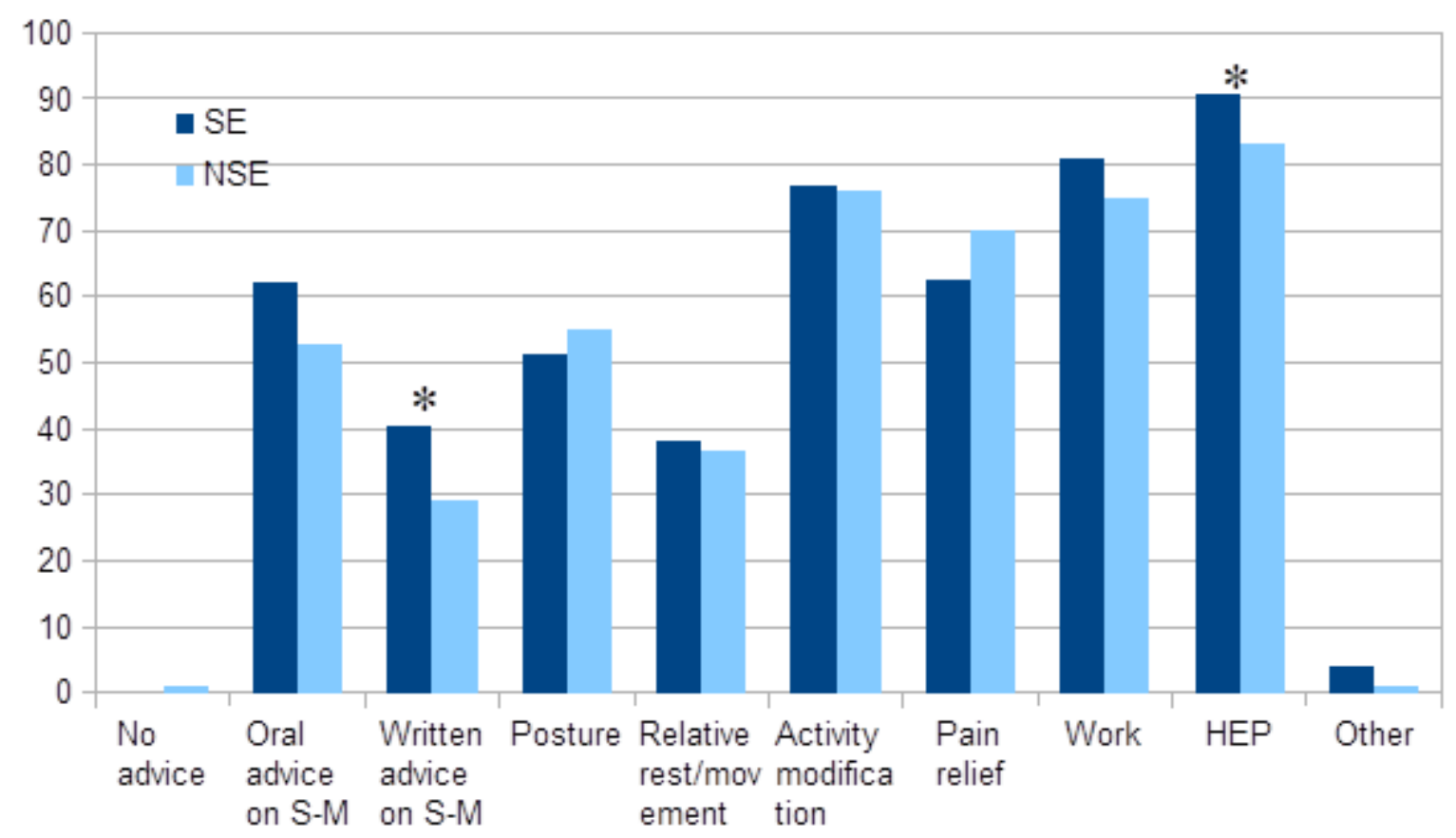

623

624

625

626

627

628

629

630

631

NOTE: Q, question number; SE, respondents who stated a specific education on rotator cuff disorders; NSE, respondents who stated no specific education on rotator cuff disorders; S-M, self-management; HEP, home exercise program; *, statistically significant difference. 